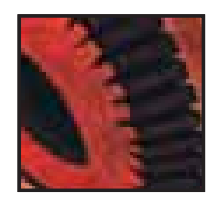

\title{
Ideas at Work
}

\section{The Expanded \\ Chronic Care Model: \\ An Integration of Concepts and Strategies from Population Health Promotion and the Chronic Care Model}

\author{
Victoria J. Barr, Sylvia Robinson, Brenda Marin-Link, Lisa Underhill, \\ Anita Dotts, Darlene Ravensdale, Sandy Salivaras
}

\begin{abstract}
Given the increasing incidence of chronic diseases across the world, the search for more effective strategies to prevent and manage them is essential. The use of the Chronic Care Model (CCM) has assisted healthcare teams to demonstrate effective, relevant solutions to this growing challenge. However, the current CCM is geared to clinically oriented systems, and is difficult to use for prevention and health promotion practitioners. To better integrate aspects of prevention and health promotion into the CCM, an enhanced version called the Expanded Chronic Care Model is introduced. This new model includes elements of the population health promotion field so that broadly based prevention efforts, recognition of the social determinants of health, and enhanced community participation can also be part of the work of health system teams as they work with chronic disease issues.
\end{abstract}

\section{INTRODUCTION}

Chronic disease is an international concern. The increasing incidence of chronic diseases is approaching epidemic levels. Chronic disease is a strain on individuals and on healthcare systems. Finding evidence-based and effective strategies to promote health and to prevent and manage chronic diseases is essential. The current situation is not encouraging. Multiple studies demonstrate that guideline-directed chronic disease care is not the norm (Wagner et al. 1999).

A variety of changes for the management of chronic disease care have been advocated (Wagner et al. 1996; World Health Organization 2002). Renders et al. (2001) concluded after a Cochrane review that the most effective interventions for improvements in chronic disease care include the combination of multi-pronged strategies. The Chronic Care Model (CCM) is an example of this type of approach. The model has been implemented by a large number of organizations in the United States, the United Kingdom and Sweden through the Chronic Illness Breakthrough Series conducted by the Institute for Health Care Improvement. Initial results of testing the model are encouraging (Wagner et al. 2001).

Proponents of the CCM have suggested that it can also be used for the prevention of chronic disease. Glasgow et al. (2001) theorize that change will be less costly and more effective if both clinical prevention and management of chronic disease use a similar set of improvement strategies. Their paper concludes that the CCM can be used to direct quality improvement initiatives 
for clinical preventive services. However, Glasgow and his colleagues acknowledge that the "scope and depth of the community resources and policy-linkage components of the CCM may need to be expanded" (Glasgow et al. 2001 79: 602). This paper proposes a strategy to address this requirement, and, at the same time, to broaden the CCM so that it is applicable to clinical preventive services and to other, broader areas of prevention and to the field of health promotion.

It is the experience of the authors of this paper that the current language of the CCM does not resonate with population health promotion practitioners who make up an integral component of publicly funded health systems. Incorporating the principles of health promotion and the focus on the determinants of health as directed by a population health approach enables the CCM to be used by the entire health team in an integrated fashion.

This article examines: (a) the challenges to the current CCM, (b) the evidence for population health promotion and (c) a proposal to expand the existing CCM to include elements of population health promotion.

\section{The Chronic Care Model (CCM)}

In the CCM, improved functional and clinical outcomes for disease management are the result of productive interactions between informed, activated patients and the prepared, proactive practice team of clinicians and healthcare professionals. Figure 1 illustrates these two spheres of the model that interact and influence systemic change for chronic disease management. The components of this integrated effort are illustrated in the top half of the model. Quality improvement teams working with this model focus their efforts and interventions on the four areas contained in the health system oval: self-management support, delivery system design, decision support and clinical information systems. Table 1 provides an overview of and examples of interventions for the key model components of the CCM.

Evidence indicates that this organized and multifaceted support for primary care teams positively affects the care of diabetic patients (McCulloch et al. 1998). Examples of functional and clinical outcomes that resulted from applying the CCM to the care of people with diabetes included decreased levels of HbA1c and a decrease in smoking rates among patients.

\section{Chalenges of the Chronic Care Model}

In their recent article, Glasgow et al. (2001) state that the changes recommended in the CCM regarding the improvement of the delivery of effective patient care are consistent with those needed to maintain effective prevention of disease and disability. Glasgow and colleagues suggest that both fields follow a common set of system changes and improvement strategies anchored in the CCM. Unfortunately, the paradigm in which these issues are discussed is narrow, evidenced by descriptors,

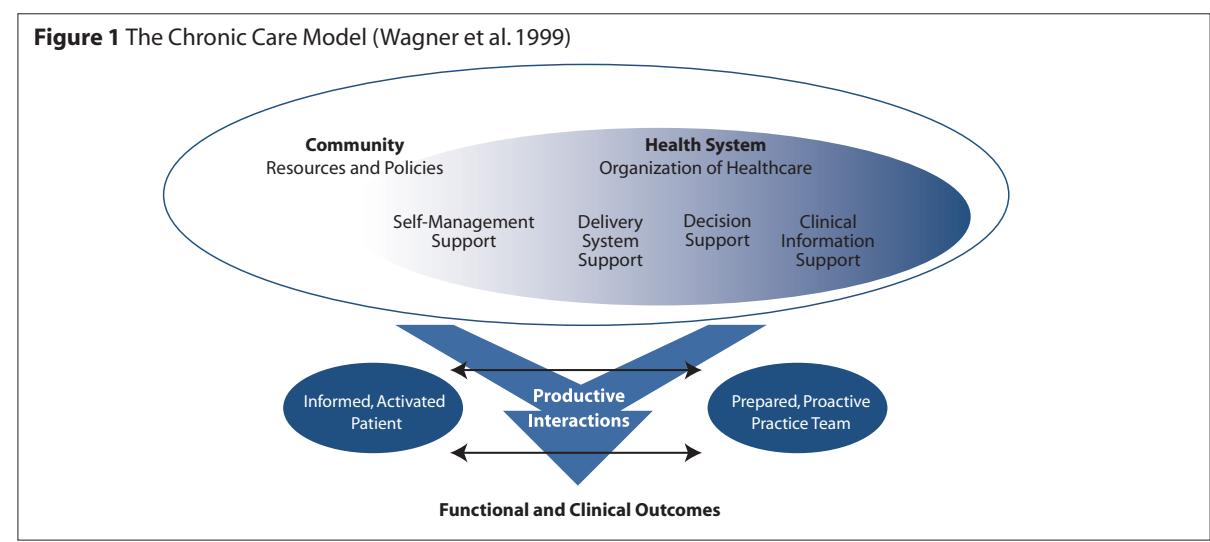

\begin{tabular}{|c|c|c|}
\hline \multicolumn{2}{|c|}{ MODEL COMPONENTS } & EXAMPLES \\
\hline $\begin{array}{l}\text { Health System - } \\
\text { Organization of Healthcare }\end{array}$ & $\begin{array}{l}\text { Program planning that includes } \\
\text { measurable goals for better care of } \\
\text { chronic illness }\end{array}$ & $\begin{array}{l}\text { - Visible support of improvements } \\
\text { provided by senior leadership } \\
\text { - Incentives for care providers }\end{array}$ \\
\hline Self-Management Support & $\begin{array}{l}\text { Emphasis on the importance of the } \\
\text { central role that patients have in } \\
\text { managing their own care }\end{array}$ & $\begin{array}{l}\text { - Educational resources, skills training } \\
\text { and psychosocial support provided to } \\
\text { patients to assist them in managing } \\
\text { their care }\end{array}$ \\
\hline Decision Support & $\begin{array}{l}\text { Integration of evidence based guide- } \\
\text { lines into daily clinical practice }\end{array}$ & $\begin{array}{l}\text { - Wide dissemination of practice } \\
\text { guidelines } \\
\text { - Education and specialist support } \\
\text { provided to healthcare team }\end{array}$ \\
\hline Delivery System Design & $\begin{array}{l}\text { Focus on teamwork and an expanded } \\
\text { scope of practice for team members } \\
\text { to support chronic care }\end{array}$ & $\begin{array}{l}\text { - Planned visits and sustained follow-up } \\
\text { - Clearly define roles of healthcare team }\end{array}$ \\
\hline Clinical Information Systems & $\begin{array}{l}\text { Developing information systems } \\
\text { based on patient populations to } \\
\text { provide relevant client data }\end{array}$ & $\begin{array}{l}\text { - Surveillance system that provides alerts, } \\
\text { recall and follow-up information } \\
\text { - Identification of relevant patient } \\
\text { subgroups requiring proactive care }\end{array}$ \\
\hline $\begin{array}{l}\text { Community Resources and } \\
\text { Policies }\end{array}$ & $\begin{array}{l}\text { Developing partnerships with } \\
\text { community organizations that } \\
\text { support and meet patients' needs }\end{array}$ & $\begin{array}{l}\text { - Identify effective programs and } \\
\text { encourage appropriate participation } \\
\text { - Referral to relevant community-based } \\
\text { services }\end{array}$ \\
\hline
\end{tabular}


such as "preventive care" and "clinical preventive services." In contrast to the representation of the prevention field offered by Glasgow et al. (2001), effective prevention of illness and disability actually moves beyond the use of clinical services to include community and inter-sectoral collaboration.

Glasgow and his colleagues (2001) acknowledge that the Community Resources and Policies component of the CCM is inadequately defined. However, their approach does not contain a re-conceptualization of the CCM to include principles of population health and health promotion. The CCM in its current form does not adequately encompass or describe the strategies needed to effectively promote health and prevent disease. For instance, if the Community Resources and Policies section of the CCM describes "barriers to achieving... [patient] goals, and especially social-environmental factors that determine long-term success" (Glasgow et al. 2001 79: 585), it must reflect the complexity and interplay of those environmental barriers. Unfortunately, healthcare has traditionally had little success in addressing the social, environmental and cultural factors that affect health. Without concerted action to address these factors, success will continue to be elusive in the efforts to prevent disability and illness.

\section{Evidence-Based Health Promotion/Population Health Models}

Operating from a set of philosophies that focus on overall health, quality of life and well-being, Canada has been a world leader in the field of health promotion: "the process of enabling people to increase control over, and to improve, their health" (World Health Organization 1986). As an alternative to lifestyle- and behaviour-based prevention efforts, health promotion aims to facilitate individual and community empowerment so that all people, both ill and well, are able to achieve a greater sense of control over the many complex factors that affect their health. Effective health promotion and prevention efforts do much more than "establish linkages with community resources relevant to chronic illness care" (Glasgow et al. 2001 79: 589-90), as recommended by the CCM. Instead, effective health promotion follows the lead of the community in addressing its needs and developing strategies to meet those needs.

In the report titled $A$ New Perspective on the Health of Canadians (Lalonde 1974), the Government of Canada publicly acknowledged that medicine and the traditional healthcare system play only a small role in determining health status. Instead, health is portrayed as being determined by the interplay of factors, including human biology, the environment and lifestyle. The lifestyle component of the report received the most attention, and efforts were directed to promote the adoption of healthier lifestyles. Canadian programming during the 1970s had a positive impact in terms of smoking (Ferrence 1989), the promotion of healthy eating habits (Labonte and Penfold 1981) and the awareness of the importance of physical activity (Cunningham 1992). However, the approach was criticized for assigning blame to individuals for their own health problems. If ill health was "caused" by poor judgement and decision-making around smoking, nutrition and physical activity patterns, then it is easy to see how individuals could feel judged by campaigns and programming that focused entirely on individual responsibility for behaviour change. There is now a growing recognition that lifestyle behaviours, such as physical activity and smoking, are influenced not only by individual choice, but also by a variety of social, economic and cultural factors inherent in the environments where people live, learn, work and play.

Research since the 1970s has demonstrated the paramount role of social, economic and environmental factors in the maintenance of health and well-being (Evans et al. 1994; Evans and Stoddart 1990). The most significant determinants of health are social and economic factors, not those most strongly linked with healthcare services or personal choices and behaviours. For instance, individuals, families and communities with low incomes are more likely to have physical, social and mental health problems than those with higher incomes. They are also more likely to die earlier than other members of the population, regardless of which cause of death is considered (Smith et al. 1996; Wilkinson 1996; World Health Organization 1998).

The gradient nature of health status suggests that it is embedded in collective factors in society, not just in individual factors (Wilkinson 1996). Recognizing the fact that health is significantly affected by policy decisions in non-healthcare areas (including housing, transportation and food distribution), the World Health Organization (WHO) called for inter-sectoral collaboration efforts to improve the conditions required for an optimal level of health and well-being. The result was the Ottawa Charter for Health Promotion (World Health Organization 1986), a document that has radically re-shaped health education and health promotion in many countries around the world. The Charter emphasizes societal change rather than individual responsibility, and supports an active role for the public in setting priorities, making decisions, planning strategies and implementing them to achieve better community health (Terris 1992). It also extends the concept of health to mean a "resource for everyday life" embodying social, environmental and personal assets and physical capacities (World Health Organization 1986). Using this broad definition, enhancing health goes far beyond how much or what type of service is provided as part of traditional healthcare services.

Instead, the influence of the social, economic and cultural determinants of health suggests the need for a comprehensive and collaborative approach to improving health that addresses root causes and tries to avert illness and injury before they occur. "Population health promotion" (Hamilton and Bhatti 1996) is becoming a common way to integrate the evidence of the 
broader determinants of health (the population health approach) with the actions of health promotion. These actions can and should be implemented at a variety of levels and sectors for them to have maximum effect. Much of the work to improve these conditions falls under the mandate of sectors outside of the traditional healthcare system, including education, justice, housing, employment and others. While the healthcare sector cannot undertake this agenda alone, it can initiate dialogue and act as a collaborator in efforts to improve the well-being of members of the population, especially with those groups that are experiencing poor health. High-quality healthcare services must be supported by policies and programs in communities that allow people time and opportunity to care for each other, without compromising their own health or financial security. The intended outcomes of population health promotion, therefore, include supported institutional, social and physical environments as well as enhanced individual and community capacities.

A population health promotion approach works to improve the underlying conditions of people's lives that enable them to be healthy. As well, it aims to reduce inequities in those conditions that place some members of the community at a disadvantage for maintaining optimal health. Population health promotion includes a variety of approaches to reach these goals. Through the proactive identification of risk behaviours and environmental conditions of client and population groups, population health promotion works to prevent problems before they occur and to avoid further problems from occurring after injury or illness is already present. The ideal result is an enhanced sense of health and quality of life for individuals and families in that community.

The North Karelia Project, a community-based health promotion program in Finland to reduce cardiovascular disorders, has demonstrated the potential of effective population health promotion at work. The project has reported both costbenefit and cost-effective analysis for its successful heart health interventions in 1972 (onset) and again in 1992. After 20 years, the cardiovascular disease mortality rate in men declined by $68 \%$, while coronary heart disease mortality in men declined by $73 \%$ (Puska et al. 1998). During the same period, Finland experienced a US\$600 million decrease in its overall cardiovascular-related social cost for those aged 35 to 64 years (Puska et al. 1995).

The Expanded Food and Nutrition Education Program (EFNEP) provides further evidence of effective health promotion at work. The EFNEP has shown that nutrition education programs benefit limited income families by improving their overall diets, resulting in delay or prevention of diet-related chronic diseases. A cost-benefit analysis of the 1996 EFNEP study in the state of Virginia found that for every US $\$ 1$ invested in the program there was a benefit of US\$17.04 in healthcare savings (Rajgopal et al. 2002).
The Higgins Nutrition Intervention Program operating out of the Montreal Diet Dispensary offers a third example of how effective health promotion can result in positive outcomes, in this case reduction of low birth weight rates among low-income women. The program targeted pregnant women who were experiencing poverty, family violence, depression, psychiatric history or health and nutritional problems. Apart from an individual nutritional assessment, women were also provided with vitamins and food supplements of milk and eggs. One study has shown that the overall rate of low birth weight was $50 \%$ lower among the intervention infants than among their siblings from a previous pregnancy without any prenatal intervention (Higgins et al. 1989).

The inclusion of a population health promotion perspective within healthcare is consistent with a shift from hospital-based care focused on illness and disability to community-oriented services that focus on the prevention of illness and disability before they have a chance to occur. The field's strong emphasis on ensuring that community members are involved in planning for new or revised services is also part of responsible and accountable healthcare management in today's climate of healthcare reform.

In this process, communities develop a stronger capacity to address the social, economic and environmental conditions affecting their health and well-being, such as poverty, social isolation and crime. As well, working from a population health promotion perspective enables administrators and governments the ability to plan programs and services with a greater confidence that these services are most needed by the people in that region.

\section{The Expanded Chronic Care Model (EXPANDED CCM)}

There is an opportunity to integrate population health promotion into the prevention and management of chronic disease. This integration would broaden the CCM by directing additional efforts to reducing the burden of chronic disease, not just by reducing the impact on those who have a disease but also by supporting people and communities to be healthy. This strategy requires action on the determinants of health as well as delivering high quality healthcare services. Glasgow et al. (2001) suggest that there are numerous advantages to having a single model for the organization of healthcare for both disease prevention and management. The integration of population health promotion into an Expanded Chronic Care Model (Expanded CCM) will address the requirement to develop the Community portion of the CCM and to guide action that would address health determinants.

The Expanded CCM supports the intrinsic role that the social determinants of health play in influencing individual, community and population health. Adopting an Expanded 


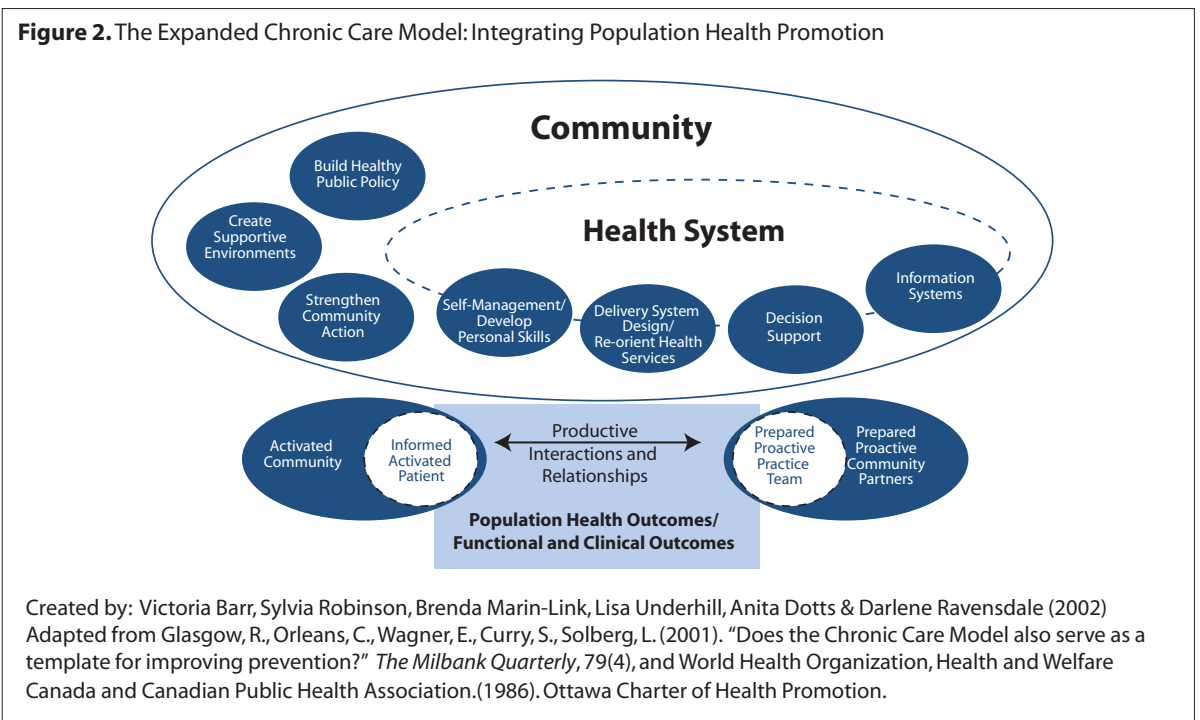

CCM will facilitate a fundamental shift in understanding about how individual client care fits within the concepts of population health. The new configuration (Figure 2) integrating the CCM with population health promotion demonstrates clear associations between the healthcare system and the community. This action-driven model will broaden the focus of practice to work towards health outcomes for individuals, communities and populations.

\section{The Health System and the Community in the Expanded Chronic Care Model}

The large inner oval in the original CCM (Figure 1) represents the health system or an individual healthcare organization. The Expanded CCM, however, includes a porous border between the formal health system and the community. This porous border is a graphical representation of the flow of ideas, resources and people between the community and the health system.

A second area of change in the Expanded CCM is the placement of the four areas of focus: self-management support, decision support, delivery system design and information systems. These four circles now straddle the border between the health system and the larger community. To address both the delivery of healthcare services and population health promotion, the activities of these four areas can be integrated within, and have an impact on, both the healthcare organization and the community.

The Ottawa Charter for Health Promotion refers to five action areas:

- develop personal skills

- re-orient health services

- build healthy public policy

- create supportive environments
- strengthen community action.

In merging these five action areas with the CCM, two of the areas of focus are re-named and re-defined, and additional detail is created in the "Community" oval. This integration of population health promotion and clinical treatment also affects the lower half of the model.

\section{Self-Management / Develop Personal Skills}

Self-Management / Develop Personal Skills refers to the support of selfmanagement in coping with a disease but also to the development of personal skills for health and wellness. The arena for action in this expanded notion of self-management includes strategies in the community as well as in the health system.

In population health promotion, supporting personal and social development of individuals and groups is done in part by providing information and enhancing life skills. It increases options available for people to exercise more control over their health and their environments. It includes but goes beyond traditional health education messages, such as those dealing with smoking, nutrition and physical activity. While traditional health education programs are important, by themselves these initiatives often have limited impact on health behaviours and/or long-term health status and therefore must be broadened to include consideration of the determinants of health.

The development of smoking cessation and tobacco use prevention programs provides good examples of efforts to develop personal skills among individuals or groups in the community. Smoking cessation advice offered by healthcare professionals is one effective way of encouraging the development and practice of personal skills. Many other cessation and prevention programs work with community, workplace and school-based groups and also involve the development of policies and other supports as a comprehensive strategy. A recent Spanish study has concluded that smoking cessation is highly cost-effective in the reduction of cardiovascular disease prevalence. In that study, the cost per life year gained from smoking cessation programs ranged from $\$ 2,600$ to $\$ 5,700$, whereas the costs per life year gained from treatment-based interventions was up to \$86,000 (Plans-Rubio 1998).

\section{Delivery System Design / Re-orient Health Services}

In population health promotion, re-orienting health services involves encouraging those in the healthcare sector to move 
beyond the provision of clinical and curative services to an expanded mandate that supports individuals and communities in a more holistic way. Such a change in the system would acknowledge the demonstrated connections between health and broader social, political, economic and physical environmental conditions. It would also facilitate connections among the social, political and medical fields and argue that it is health, and not illness that should underpin healthcare work. This action includes a stronger emphasis on health research. Delivery system design/re-orienting health services to support both healthcare and population health promotion implies a tighter connection with the community where the system redesign activities affect citizen organizations, non-profit groups and the healthcare organization.

The healthcare sector is an essential partner in creating the proper conditions for health in society. Its leadership role in society can be exercised by providing examples of what can be done to achieve a healthy environment, or by acting as an advocate for healthy public policies. If healthcare professionals can be re-oriented to become advocates for health, rather than simply part of the repair service, they can become powerful allies for those seeking to promote health.

\section{Decision Support}

Decision support of professionals and lay people is useful both in dealing with the impact of disease and making choices that support health and well-being. Because this area of focus in the Expanded CCM straddles the health system and the community, it now encompasses the gathering of evidence not only on disease and treatment but also on strategies for being well and staying healthy. Within the healthcare organization, the work of a general practitioner can be paired with that of a specialist. Likewise, in the community, that same general practitioner can partner with a health promotion professional who has specialized knowledge in community-based best practice.

\section{Information Systems}

The use of information systems is key in supporting processes for change. In clinical informatics, information systems can be used to make the case for new programs, evaluate established ones and support new ways of working. However, information is no less powerful a tool in community activation, prevention and population health promotion.

In population health promotion, as in other areas of the health system, information about demographics, the health of the population and cultural, social and economic trends is combined with needs and strengths assessments that are led by community groups. Both types of information are considered important in planning for programs, policies and other initiatives that work to anticipate health concerns before they have a chance to occur. For instance, the province of Saskatchewan has developed a Population Health Framework for local healthcare districts (Saskatchewan Health 1999). This framework is to be used to address the unique and individual needs of each community, and encourages each local group to use various types of data to more fully understand the needs of the people in that region. Implementing the principles and strategies of population health promotion effectively requires a good understanding of the specific social and economic context within which healthcare and other services are working.

In the Expanded CCM, information systems are more broadly based. In the model, a large variety of users will now require linked products from information systems. Examples of new users include municipalities, local advocacy groups, recreation centres and service clubs. These users need to know about the community beyond the experience of patients within the healthcare system. Examples of new data needs include: the proportion of the community living in poverty, the availability of public transportation and the violent crime rate. A challenge in building these information systems is that community-based users will demand an integrated picture of not only clinical and functional outcomes but also of population health outcomes.

\section{Build Healthy Public Policy}

The development and implementation of policies designed to improve population health involves working towards organizational and governmental policy and legislation that fosters greater equity in society and leads to ensuring safer and healthier goods, services and environments. This approach combines diverse but complementary approaches including legislation, fiscal measures, taxation and organizational change. The aim is to make the healthier choice the easier choice, not only for individuals but for companies, organizations and governments as well. For example, nutrition policies have been recognized internationally as appropriate interventions for the promotion of healthy eating and the reduction of diet-related chronic disease (Edwards 1996). The most common policy options utilized for the promotion of healthy diets include the establishment and dissemination of dietary guidelines, as well as macro-level economic interventions, such as reducing the price of whole wheat flour or lowering the duty on imported fruits (Posner et al. 1994).

\section{Create Supportive Environments}

Based on the evidence that describes the significant impact of social supports on overall health and quality of life, creating supportive environments entails working to generate living and employment conditions that are safe, stimulating, satisfying and enjoyable. This action area goes beyond the obvious need for measures to protect and sustain the quality of the natural biophysical environment; it includes strategies to foster conditions for optimal levels of health in social and community 
environments (Rootman and Goodstadt 1996).

Efforts to maintain older people in their homes for as long as possible provide a good example of creating supportive environments. The provision of safe, accessible, good-quality housing with outdoor lighting, along with opportunities for social interaction and public transportation can enhance the health and quality of life for the elderly and reduce their need for healthcare and other social services (Sarwari et al. 1998).

\section{Strengthen Community Action}

This action area involves working with community groups to set priorities and achieve goals that enhance the health of the community. The empowerment of communities is key to this process. By encouraging effective public participation, health promotion aims to support people in finding their own ways of managing the health of their community.

Healthcare and other professionals can play a role in mobilizing communities to promote health, drawing upon their knowledge of the determinants of health and their power as leaders in the community. Two possible roles are suggested by the International Union of Health Promotion and Education (2000): mobilization of communities to create healthy environments, and various forms of advocacy. The Healthy Communities/Healthy Cities movement worldwide provides a good example of the former strategy (Ashton 1992). The evidence for the effectiveness of the Healthy Communities initiative in Canada demonstrates that its value lies in its ability to involve multiple partners at the community level to build a shared vision, seek consensus and take action on local concerns.

When healthcare professionals take on an advocacy role, they work with community groups to identify and remove barriers to healthy living and quality of life for particular individuals and groups in the community. For instance, in media advocacy, healthcare professionals and others provide expert input and support the dissemination of healthy messages.

\begin{tabular}{|c|c|c|c|c|}
\hline \multicolumn{2}{|c|}{ COMPONENTS OF THE CHRONIC CARE MODEL } & \multicolumn{2}{|c|}{$\begin{array}{l}\text { COMPONENTS OF THE } \\
\text { EXPANDED CHRONIC CARE MODEL }\end{array}$} & \multirow[t]{2}{*}{ EXAMPLES } \\
\hline $\begin{array}{l}\text { Health System - } \\
\text { Organization of Healthcare }\end{array}$ & $\begin{array}{l}\text { Program planning that } \\
\text { includes measurable goals for } \\
\text { better care of chronic illness }\end{array}$ & & & \\
\hline $\begin{array}{l}\text { Self-Management } \\
\text { Support }\end{array}$ & $\begin{array}{l}\text { Emphasis on the } \\
\text { importance of the central } \\
\text { role that patients have in } \\
\text { managing their own care }\end{array}$ & $\begin{array}{l}\text { Self-Management / } \\
\text { Develop Personal Skills }\end{array}$ & $\begin{array}{l}\text { Enhancing skills and } \\
\text { capacities for personal } \\
\text { health and wellness }\end{array}$ & $\begin{array}{l}\text { - Smoking prevention and cessation } \\
\text { programs } \\
\text { - Seniors' walking programs }\end{array}$ \\
\hline Decision Support & $\begin{array}{l}\text { Integration of evidence- } \\
\text { based guidelines into } \\
\text { daily clinical practice }\end{array}$ & Decision Support & $\begin{array}{l}\text { Integration of strategies } \\
\text { for facilitating the } \\
\text { community's abilities to } \\
\text { stay healthy }\end{array}$ & $\begin{array}{l}\text { - Development of health promotion } \\
\text { and prevention "best practice" } \\
\text { guidelines }\end{array}$ \\
\hline Delivery System Design & $\begin{array}{l}\text { Focus on teamwork and } \\
\text { an expanded scope of } \\
\text { practice to support } \\
\text { chronic care }\end{array}$ & $\begin{array}{l}\text { Delivery System Design / } \\
\text { Re-orient Health Services }\end{array}$ & $\begin{array}{l}\text { Expansion of mandate to } \\
\text { support individuals and } \\
\text { communities in a more } \\
\text { holistic way }\end{array}$ & $\begin{array}{l}\text { - Advocacy on behalf of (and with) } \\
\text { vulnerable populations } \\
\text { - Emphasis in quality improvement } \\
\text { on health and quality of life } \\
\text { outcomes, not just clinical } \\
\text { outcomes }\end{array}$ \\
\hline $\begin{array}{l}\text { Clinical Information } \\
\text { Systems }\end{array}$ & $\begin{array}{l}\text { Developing information } \\
\text { systems based on patient } \\
\text { populations to provide rele- } \\
\text { vant client data }\end{array}$ & Information Systems & $\begin{array}{l}\text { Creation of broadly based } \\
\text { information systems to } \\
\text { include community data } \\
\text { beyond the healthcare } \\
\text { system }\end{array}$ & $\begin{array}{l}\text { - Use of broad community needs } \\
\text { assessments that take into } \\
\text { account: } \\
\text { - poverty rates } \\
\text { - availability of public } \\
\text { transportation } \\
\text { - violent crime rate }\end{array}$ \\
\hline \multirow[t]{3}{*}{$\begin{array}{l}\text { Community } \\
\text { Resources and Policies }\end{array}$} & $\begin{array}{l}\text { Developing partnerships } \\
\text { with community organi- } \\
\text { zations that support and } \\
\text { meet patients' needs }\end{array}$ & $\begin{array}{l}\text { Build Healthy Public } \\
\text { Policy }\end{array}$ & $\begin{array}{l}\text { Development and imple- } \\
\text { mentation of policies } \\
\text { designed to improve } \\
\text { population health }\end{array}$ & $\begin{array}{l}\text { - Advocating for / developing: } \\
\text { - smoking bylaws } \\
\text { - walking trails } \\
\text { - reductions in the price of whole } \\
\text { wheat flour }\end{array}$ \\
\hline & & $\begin{array}{l}\text { Create Supportive } \\
\text { Environments }\end{array}$ & $\begin{array}{l}\text { Generating living and } \\
\text { employment conditions that } \\
\text { are safe, stimulating, } \\
\text { satisfying and enjoyable }\end{array}$ & $\begin{array}{l}\text { - Maintaining older people in their } \\
\text { homes for as long as possible } \\
\text { - Work towards the development of } \\
\text { well-lit streets and bicycle paths }\end{array}$ \\
\hline & & $\begin{array}{l}\text { Strengthen Community } \\
\text { Action }\end{array}$ & $\begin{array}{l}\text { Working with community } \\
\text { groups to set priorities and } \\
\text { achieve goals that enhance } \\
\text { the health of the community }\end{array}$ & $\begin{array}{l}\text { - Supporting the community in } \\
\text { addressing the need for safe, } \\
\text { affordable housing }\end{array}$ \\
\hline
\end{tabular}




\section{Outcomes in the Expanded Chronic Care Model}

In the original CCM, improved functional and clinical outcomes ideally result from interactions between the prepared, proactive practice team and the informed, activated patient. In the Expanded CCM, this concept is preserved and enhanced. Improved health of the population results from positive and productive interactions and relationships among community members, healthcare professionals, organizations, individuals and community groups. Outcomes include population health outcomes as well as individual functional and clinical outcomes.

A broader population health perspective requires us to look at not only clinical/functional outcomes but measures for the population as well. For example, when dealing with specific diseases, such as diabetes, these may include rates in the population of the clinical measures (percentage of the population with an $\mathrm{HbA} 1 \mathrm{c}<8 \%$ ). In addition, a population health approach requires us also to assess broader variables, such as poverty rates in a community, and issues of transportation and food security.

Glasgow et al. (1999) suggests that there is a need to re-frame chronic diseases, such as diabetes, from a clinical disease to a public health issue. This important perspective briefly acknowledges issues of equity and an enhanced patient/community quality of life in the context of the broader factors that influence self-management and patient care, but stops short of a full exploration of the implications for outcome measurement. The population health approach requires an explicit examination of the determinants of health. This requires the measurement of distribution of outcome indicators, such as the incidence of diabetes by such variables as income and education.

The incorporation of population health promotion into the CCM also requires practitioners to broaden definitions of outcomes and to determine new ways to measure them. In particular, for short-term and intermediate population health outcomes, projects may wish to track measures, such as the existence of public policies to support health, citizen participation in community decision-making and social cohesion.

\section{Conclusion}

The burden of chronic disease is expected to continue to escalate as the population ages. It is essential for healthcare organizations to quickly find effective ways in which to deal with this impending crisis (World Health Organization 2002). The Chronic Care Model (Wagner et al. 1999) offers a framework that re-orients healthcare services to effectively deal with the needs and concerns of individuals with chronic disease. By exerting effort in multiple areas simultaneously, the CCM encourages practitioners to focus on the improvement of functional and clinical outcomes for clients.

While the CCM has certainly been helpful for a number of centres in various parts of the world, it does not reflect the diversity and complexities of those aspects of prevention and health promotion that go beyond clinical preventive services. As well, the current CCM presents a narrow perspective of the roles that both informal and formal community supports play in improving health. The functions of health promotion and disease/injury prevention in the community are not explicit in the original CCM. The ways in which the fields of health promotion and healthcare can and do work together need to be reflected.

The fields of population health and health promotion, brought together by the term "population health promotion," recognize and work with the broader determinants of health (e.g., housing, income, social supports) that can often serve as barriers for both individuals and communities to maintain optimum health. Such an approach includes creating public policies that promote health, strengthening community action, and creating supportive environments. As well, population health promotion works to develop personal and coping skills, and to re-orient health services so that they reflect a greater emphasis on prevention and public health issues. Such an approach, as presented here, includes community participation in planning, implementation and evaluation of programming and policy development. While this work can sometimes involve a long-term effort, practitioners in this field have demonstrated successful health

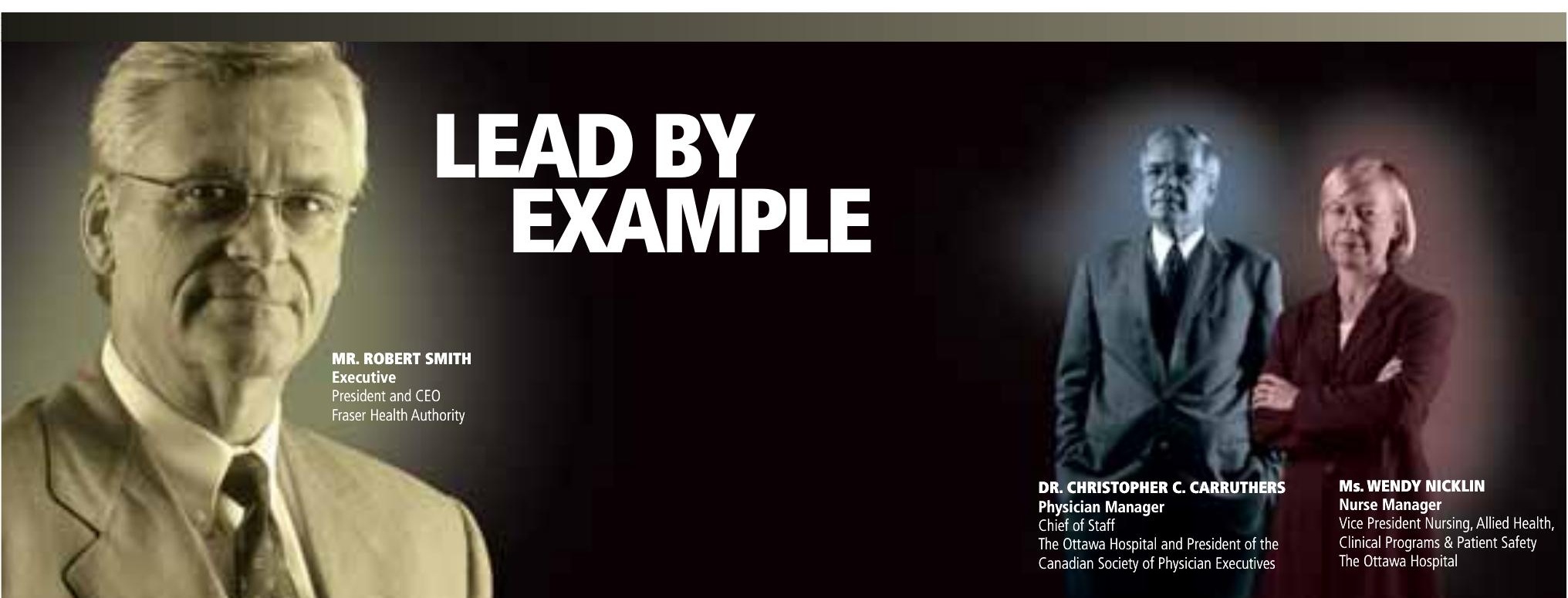


outcomes that have effectively reduced healthcare costs and resulted in improved quality of life for clients and families.

The Expanded Chronic Care Model described here merges population health promotion with clinical healthcare services and takes a first step in describing how these two approaches can complement one another. In real-life situations, the results include broader, interdisciplinary, and inclusive teams that work directly with community supports and leadership to deal with a client's current health concerns by addressing those issues that may lie at the root of some of these problems and are presenting barriers to his or her improvement. As well, the team may use the knowledge of those barriers to support the community in addressing issues, such as food security, social isolation or transportation. By working on both the prevention and treatment ends of the continuum from such a broad perspective, healthcare and other teams represent the best potential for improved health outcomes in the long term. It is this combined approach of effective population health promotion and improved treatment of disease, as suggested by the Expanded CCM, that will be our best weapon against the mounting burden of chronic disease.

\section{Future Research and Directions}

We hope that the introduction of the Expanded CCM will generate further debate and discussion around the importance of coordinated and effective prevention and management of chronic conditions. Healthcare organizations will also need to test this new model in a variety of settings. Program evaluation and other types of research that involves community members, such as participatory action research, may be particularly beneficial in testing the implementation of the Expanded CCM. Such implementation will enable the development of new ways to support clients of health systems and the communities in which they live, as well as more comprehensively integrate prevention strategies into the work of healthcare. The challenge of more effectively managing and preventing chronic disease will require such a set of diverse and innovative approaches. IQ

\section{References}

Ashton, J. 1992. Healthy Cities. Buckingham, UK: Open University Press.

Cunningham, R. 1992. Promoting Better Health in Canada and the USA: A Political Perspective. Toronto: The Centre for Health Promotion, University of Toronto/ParticipACTION.

Edwards, G. 1996. Building Healthy Public Policy. Toronto: The Centre for Health Promotion/ParticipACTION.

Evans, R.G., M.L. Barer and T.G. Marmor, eds. 1994. Why Are Some People Healthy and Others Not? The Determinants of Health of Populations. New York: Aldine de Gruyter.

Evans, R.G. and G.L. Stoddart. 1990. "Producing Health, Consuming Health Care." Social Science and Medicine 31(12): 1347-63.

Ferrence, R.G. 1989. Deadly Fashion: The Rise and Fall of Cigarette Smoking in North America. New York: Garland.

Glasgow, R., C. Orleans, E. Wagner, S. Curry and L. Solberg. 2001. "Does the Chronic Care Model also Serve as a Template for Improving Prevention?” The Milbank Quarterly 79(4): 579-612.

Hamilton, N., and T. Bhatti. 1996. Population Health Promotion: An Integrated Model of Population Health and Health Promotion. Ottawa: Health Canada.

Higgins, A.C., J.E. Moxley, P.B. Pencharz, D. Mikolainis and S. Dubois. 1989. "Impact of the Higgins Nutrition Intervention Program on Birth Weight: A Within-Mother Analysis." Journal of the American Dietetic Association 89(8): 1097-1103.

International Union for Health Promotion and Education. 2000. The Evidence of Health Promotion Effectiveness: Shaping Public Health in a New Europe. London, UK: European Commission.

Labonte, R. and S. Penfold. 1981. Canadian Perspectives in Health Promotion: A Critique. Health Education 19(3-4): 4-9.

Lalonde, M. 1974. A New Perspective on the Health of Canadians. Ottawa: Information Canada.

McCulloch, D., M. Price, M. Hindmarsh and E. Wagner. 1998. "A Population-Based Approach to Diabetes Management in a Primary Care Setting: Early Results and Lessons Learned." Effective Clinical Practice, American College of Physicians-American Society of Internal Medicine 1(1):12-22.

Plans-Rubio, P. 1998. "Cost-Effectiveness of Cardiovascular Prevention Programs in Spain." International Journal of Technology Assessment in Health Care 14: 320-30.
In today's constrained health care system, every administrative decision you make is critical. To make wise choices, you rely on your experience and training. Yet volumes of insightful research findings exist that could offer additional guidance as you seek to gain efficiencies, maximize resources and improve patient care and outcomes. But just how can you access that research, interpret the findings and apply the recommendations to the day-to-day administration of your health care organization?

With strategic training on how to incorporate health service research in the decision-making process from the Executive Training for Research Application (EXTRA) Fellowship Program.
EXTRA is a challenging and rewarding two-year program that combines residency seminars, e-learning, mentorship and networking components with intervention projects undertaken in fellows' home institutions. Delivered by an expert faculty drawn from both Canada and abroad, EXTRA is an exceptional professional development opportunity available to participants in their choice of French or English. The program encourages health service executives, physician managers and nurse managers to become better leaders, initiate a cultural shift within their health organizations toward evidence-based decision-making and inspire positive, effective change throughout the Canadian health care system.

\section{EXTRA call for applications. Available online December 2003.} www.chsrf.ca/extral

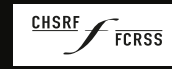


The Expanded Chronic Care Model

Victoria J. Barr et al.

Posner, B. M., P.A. Quartromoni and M. Franz. 1994. "Nutrition Policies and Interventions for Chronic Disease Risk Reduction in International Settings." Nutrition Reviews 52(5): 179-87.

Puska, P., J. Tuomilehto, A. Nissinen and E. Vartiainen. 1995. "The North Karelia Project: 20 Year Results and Experiences." Helsinki, Finland: The National Public Health Institute.

Puska, P., E. Vartiainen, J. Tuomilehto, V. Salomaa and A. Nissinen. 1998. "Changes in Premature Deaths in Finland: Successful Long-Term Prevention of Cardiovascular Diseases." Bulletin of the World Health Organization 76(4): 419-25.

Rajgopal, R., R.H. Cox, M. Lambur and E.C. Lewis. 2002. "Cost-Benefit Analysis Indicates the Positive Economic Benefits of the Expanded Food and Nutrition Education Program Related to Chronic Disease Prevention." Journal of Nutrition Education and Behavior 34(1): 26-37.

Renders, C., G. Valk, S. Griffin, E. Wagner, J. Eijk Van and W. Assendelft. 2001. "Interventions to Improve the Management of Diabetes in Primary Care, Outpatient, and Community Settings." Diabetes Care 24(10): 1821 33.

Rootman, I. and M.S. Goodstadt. 1996. Health Promotion and Health Reform in Canada. Toronto: Centre for Health Promotion, University of Toronto.

Sarwari, A. R., L. Fredman, P. Langenberg and J. Magaziner. 1998. "Prospective Study on the Relation Between Living Arrangement and Change in Functional Health Status of Elderly Women." American Journal of Epidemiology 147(4): 370-8.

Saskatchewan Health. 1999. A Population Health Promotion Framework for Saskatchewan Health Districts. Regina, SK: Saskatchewan Health, Population Health Branch.

Smith, G. D., J. D. Neaton, D. Wentworth, R. Stamler and J. Stamler. 1996. "Socioeconomic Differentials in Mortality Risk Among Men Screened for the Multiple Risk Factor Intervention Trial: I. White Men." American Journal of Public Health 86: 486-96.

Terris, M. 1992. Concepts of Health Promotion: Dualities in Public Health Theory." Journal of Public Health Policy 13(3): 267-76.

Wagner, E. H. 1999. "Care of Older People with Chronic Illness.” In E. Calkins, C. Boult and E. H. Wagner, eds., New Ways to Care for Older People: Building Systems Based on Evidence. (39-64) New York: Springer.

Wagner, E. H., B. Austin and M. Von Korff. 1996. "Organizing Care for Patients with Chronic Illness.” The Milbank Quarterly 74(4): 511 44 .

Wagner, E. H., C. Davis, J. Schaefer, M. Von Korff and B. Austin. 1999. "A Survey of Leading Chronic Disease Management Programs: Are They Consistent with the Literature?" Managed Care Quarterly 7(3): 56-66

Wagner, E. H., R. Glasgow, C. Davis, A. Bonomi, L. Provost, D. McCulloch, P. Carver and C. Sixta. 2001. "Quality Improvement in Chronic Illness Care: A Collaborative Approach.” Journal on Quality Improvement 27(2): 63-80.

\section{Reduce Costs and} Improve Efficiency...

with a call center system from 1Call!

We'll help you design a call center system that operates at maximum efficiency, saving money while increasing productivity and patient satisfaction.

Choose from 1Call's powerful modular solutions:

CTI PC-based Operator Console $\triangleleft$ On-Call Scheduling

$\uparrow$ IT and PBX Integration $\uparrow$ Physician Answering / Paging

Appointment and Class Scheduling $\triangleleft$ IVR $\triangleleft$ Help Desk

$\downarrow$ And much more!

\section{Great Communications begin with}
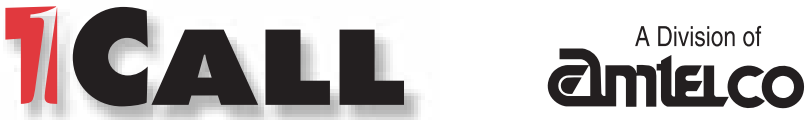

4800 Curtin Drive $\bullet$ McFarland, WI $53558 \cdot(800) 356-9148$

145 N. Service Road, Ste. $200 \cdot$ Burlington, ONT L7L 6A3 • (800)238-9223 www.1call.com•info@1call.com
Wilkinson, R.G. 1996. "Unhealthy Societies: From Inequality to Wellbeing.” New York: Routledge.

World Health Organization. 1986. The Ottawa Charter for Health Promotion. Copenhagen: World Health Organization Regional Office for Europe.

World Health Organization. 1998. The Solid Facts: Social Determinants of Health. Geneva: World Health Organization.

World Health Organization. 2002. Innovative Care for Chronic Conditions: Building Blocks for Action.Geneva: World Health Organization.

\section{About the Authors \\ Victoria J. Barr, MHSc, is with the Vancouver Island Health Authority.}

Sylvia Robinson, MPH, is with the Vancouver Island Health Authority.

Brenda Marin-Link, RN, MBA, is with the Vancouver Island Health Authority.

Lisa Underhill, RN, MN, is with the Vancouver Island Health Authority.

Anita Dotts, RN, BScN, is with the James Bay Community Project.

Darlene Ravensdale, RD, MSc, is with the Vancouver Island Health Authority.

Sandy Salivaras, BA, is with the Vancouver Island Health Authority. 